\title{
Investigating a Quadruplex-Ligand Interaction by Unfolding Kinetics
}

\author{
Jeremy J. Green, Sylvain Ladame, Liming Ying, David Klenerman*, and Shankar \\ Balasubramanian* \\ Contribution from the Department of Chemistry, University of Cambridge, Lensfield Road, \\ Cambridge, CB2 1EW, U.K.
}

\begin{abstract}
We have investigated the interaction of the intramolecular human telomeric DNA G-quadruplex with a hemicyanine-peptide ligand, by studying the rate of quadruplex opening with a complementary DNA oligonucleotide. By employing a minimal kinetic model, the relationship between the observed rate of quadruplex opening and the ligand concentration has enabled estimation of the dissociation constant. A van't Hoff analysis revealed the enthalpy and entropy changes of binding to be $-77 \pm 22 \mathrm{~kJ} \mathrm{~mol}^{-1}$ and $-163 \pm 75 \mathrm{~J} \mathrm{~mol}^{-1} \mathrm{~K}^{-1}$, respectively. Arrhenius analyses of the rate constants of opening free and bound quadruplex gave activation energies of $118 \pm 2$ and $98 \pm 10 \mathrm{~kJ} \mathrm{~mol}^{-1}$, respectively. These results indicate that the presence of the ligand has only a small effect on the activation energy, suggesting that the unbinding of the ligand occurs after the transition state for quadruplex unfolding.
\end{abstract}

\section{Introduction}

DNA sequences containing guanine stretches can form four-stranded structures called Gquadruplexes. 1 Such structures arise due to the ability of guanine to hydrogen bond in a cyclical fashion to form tetrads.2 Quadruplexes are further stabilized by the coordination of interstitial cations (e.g., $\mathrm{Na}^{+}$and $\mathrm{K}^{+}$). There is growing evidence to suggest that quadruplexes may have a biological role. Several naturally occurring proteins have been identified that interact with quadruplex DNA in preference to duplex DNA.3-5 Telomeric DNA has been shown to form quadruplexes under pseudo-physiological conditions, 6 and stabilization of the telomeric quadruplex has been shown to inhibit the action of telomerase. 7 Furthermore, putative quadruplex-forming motifs have been identified throughout the genome.8,9 There has been a particular focus on nontelomeric quadruplexes in the promoter regions of genes.10-15 The case of the c-myc quadruplex has been well-studied and shown to act as a negative regulator of this gene.16-18 Quadruplexes are thus emerging as a broad class of targets for small molecule-based intervention in biology. Several classes of quadruplex ligands have been developed.19,20 We previously reported a quadruplexspecific family of ligands made by conjugating a hemicyanine to a series of tetrapeptides selected by combinatorial methods. 21

Intramolecular quadruplexes can comprise several interconverting conformations, 18,22 which has prompted the study of quadruplex dynamics.22-25 In particular, a number of

(C) 2006 American Chemical Society

E-mail: sb10031@cam.ac.uk; dk10012@cam.ac.uk.

Supporting Information Available: Justification and derivation of the method used to analyze the kinetics data. This material is available free of charge via the Internet at http://pubs.acs.org. 
studies have been carried out on the kinetics of quadruplex unfolding using a complementary oligonucleotide (or mimic) as a hybridization trap.24 It has been observed that the rate of quadruplex opening can be independent of complementary strand concentration, 23 implying that some disruption of the quadruplex is a prerequisite of duplex formation. Furthermore, it has been shown by mass spectrometry that the presence of the quadruplex-binding ligand telomestatin is capable of further slowing the rate of quadruplex opening.26 Fluorescence resonance energy transfer (FRET) is a convenient method for studying biomolecular dynamics and has been applied to quadruplexes.23-24,27

Figure 1 (not drawn to scale) shows the experimental design of a system developed previously by us to study quadruplex opening.24 Hybridization of oligonucleotide III to the complementary region of $\mathbf{I}$ traps the opened quadruplex as a duplex. The concomitant separation of donor (tetramethylrhodamine, TMR) and acceptor (Cy5) fluorophores causes a large decrease in FRET, enabling the unfolding kinetics to be monitored by changes in fluorescence.

We previously reported a hemicyanine-based quadruplex ligand (HC, Figure 2) that was shown, by SPR, to bind the human telomeric quadruplex in a 1:1 stoichiometry with 50 fold discrimination in favor of quadruplex recognition as compared to duplex.21 In this article, we report on experiments that studied the influence of $\mathbf{H C}$ on the opening kinetics of the human intramolecular telomeric quadruplex.

\section{Materials and Methods}

$1 \mathrm{M}$ Tris $\cdot \mathrm{HCl}(\mathrm{pH}$ 7.4) was purchased from Sigma (Dorset, UK) and solid $\mathrm{NaCl}$ was purchased from Breckland (Norfolk, UK). Deionized water was obtained from an Elga Maxima or a MilliPore Milli-QpLuS and used throughout. Fluorescence measurements were taken using an Aminco-Bowman Series 2 fluorimeter equipped with a water bath. DNA was annealed in buffer by heating to $90^{\circ} \mathrm{C}$ for at least $10 \mathrm{~min}$, followed by slow cooling to room temperature. Annealed samples were stored at $4{ }^{\circ} \mathrm{C}$.

The fluorophore-labeled DNA oligonucleotides I and II used in this study were purchased from Cruachem (Glasgow, UK). Unlabeled DNA oligonucleotide III was purchased from Oswel (Southampton, UK). The sequences of these oligonucleotides are given below, and the chemical structures of the modifications are given in the Supporting Information.

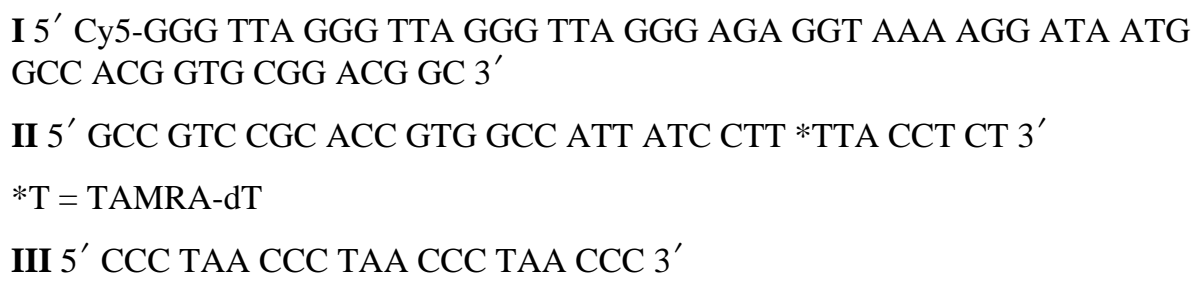

I contains the human telomeric repeat motif, $5^{\prime}$-GGG TTA GGG TTA GGG TTA GGG-3', which can form an intramolecular G-quadruplex,6,29 with Cy5 coupled to the $5^{\prime}$ terminus. II is the complement of the 35-nucleotide overhang of $\mathbf{I}$, with TMR coupled to a thymine (T28) via a six-carbon linkage. III is the complement of the quadruplex-forming region of $\mathbf{I}$. DNA concentrations were determined by absorbance at $260 \mathrm{~nm}$. The absorbances at $555 \mathrm{~nm}$ for TMR and $649 \mathrm{~nm}$ for Cy5 were used to check the purities of the labeled samples. The quadruplex-binding ligand HC (Figure 2) was synthesized and purified as described.21

To show the effect of the ligand on the rate of hybridization of the quadruplex to its complement, several kinetics runs were performed in the presence of 0-54 $\mu \mathrm{M} \mathrm{HC}$. In each run, a solution of $\mathbf{H C}$ and $10 \mathrm{nM} \mathrm{I:II} \mathrm{in} 10 \mathrm{mM}$ Tris. $\mathrm{HCl}$ (pH 7.4) and $100 \mathrm{mM} \mathrm{NaCl}$ was 
prepared from stocks held at $20^{\circ} \mathrm{C}$. The intensity of the fluorescence emission of TMR, exciting at $500 \mathrm{~nm}$ or at $515 \mathrm{~nm}$ while monitoring at $580 \mathrm{~nm}$, was followed for $100 \mathrm{~s}$. If the signal was found to be systematically changing, it was allowed to stabilize. Then, a small volume of solution containing $\mathbf{I I I}$, also at $20^{\circ} \mathrm{C}$, was added at time $t=0$ to give a final concentration of $100 \mathrm{nM}$. The progress of the hybridization was monitored by following the increase in TMR (donor) fluorescence as the duplex formed. This was repeated at temperatures of 10,15 , and $25^{\circ} \mathrm{C}$. At higher temperatures, the opening rate becomes fast relative to the mixing time preventing accurate determination of kinetic parameters.

Nitrogen gas was passed through the sample chamber at low temperature in order to prevent condensation.

The resulting traces were fitted to both single exponential (eq 1) and double exponential (eq 2) using the Solver module of Microsoft Excel. $\tau, \tau_{1}$, and $\tau_{2}$ represent the time constants of the exponential components, and $A, A_{1}$, and $A_{2}$ represent their respective amplitudes, where $A_{1}>A_{2}$. $C$ is the fluorescence at $t=\infty$, and $F$ is the measured fluorescence intensity.

$$
\begin{gathered}
F=A \exp (-t / \tau)+C \\
F=A_{1} \exp \left(-t / \tau_{1}\right)+A_{2} \exp \left(-t / \tau_{2}\right)+C
\end{gathered}
$$

The observed rate constant of quadruplex opening, $k_{\mathrm{obs}}$, was calculated as the inverse of the time constant of a single-exponential increase, or, where a double exponential gave a significantly better fit, as the time constant of the major component (generally found to be about $80 \%$ of the total amplitude) of a double-exponential process. This is summarized in eq 3.

$$
k_{\mathrm{obs}}= \begin{cases}(1 / \tau) & \text { Single-exponential decay } \\ \left(1 / \tau_{1}\right) & \text { Double-exponential decay }\end{cases}
$$

A minimal kinetic scheme for quadruplex opening is given in Figure 3. If $k_{\mathrm{on}}[\mathbf{L}]+k_{\mathrm{off}} \gg k_{1}$ and $k_{2}$, then during quadruplex opening $\mathbf{Q}, \mathbf{L}$ and $\mathbf{Q} \mathbf{L}$ are in fast equilibrium with dissociation constant $K_{\mathrm{d}}=k_{\mathrm{off}} / k_{\mathrm{on}}=[\mathbf{Q}][\mathbf{L}] /[\mathbf{Q L}]$. In this case, the observed rate of hybridization, $k_{\mathrm{obs}}$, is only related to $k_{1}, k_{2}, K_{\mathrm{d}}$, and [L] as given in eq 4 (see the Supporting Information for derivation).

$$
k_{\mathrm{obs}}=\left(k_{2}-k_{1}\right) \frac{[\mathbf{L}]}{K_{\mathrm{d}}+[\mathbf{L}]}+k_{1}
$$

Graphs of $k_{\text {obs }}$ versus [HC] (i.e., where $\mathbf{L}=\mathbf{H C}$ ) were fitted to eq 4 using the nonlinear curve-fitting software Grace 5.1.12, to evaluate $K_{\mathrm{d}}, k_{1}$, and $k_{2}$.

\section{Results \\ Kinetic Model}

Figure 3 shows a minimal kinetic scheme devised to study the influence of a ligand $(\mathbf{L})$ on the opening of a quadruplex, $\mathbf{Q}$, to give a duplex, $\mathbf{D}$. $\mathbf{Q} \mathbf{L}$ is the complex formed by $\mathbf{Q}$ and $\mathbf{L}$. $k_{\text {on }}$ and $k_{\text {off }}$ are the association and dissociation rate constants, respectively, for the binding of $\mathbf{L}$ to $\mathbf{Q}$. $k_{1}$ and $k_{2}$ are the rate constants for the opening of $\mathbf{Q}$ and $\mathbf{Q} \mathbf{L}$, respectively. This model assumes that hybridization is irreversible, which is supported by our previous experiments on this quadruplex, where duplex formation in the absence of a ligand went to 
completion at concentrations of strand $\mathbf{C}$ lower than those used here.23 The analysis was simplified by assuming that the concentrations of $\mathbf{C}$ and $\mathbf{L}$, which were at least 10 times that of $\mathbf{Q}$, are constant throughout the hybridization process.

The quadruplex system I:II was characterized by UV melting, CD spectroscopy, and fluorescence spectroscopy as described previously.23 Figure 4 shows fluorescence traces produced by quadruplex opening experiments performed in the presence of $100 \mathrm{mM} \mathrm{NaCl}$ at $20{ }^{\circ} \mathrm{C}$, along with single exponential (eq 1 ) fits to the data. These data clearly show that quadruplex opening is slowed by the presence of the ligand. This was repeated at various temperatures. At 10 and $15{ }^{\circ} \mathrm{C}$, it was observed that a second exponential component ( 20\% of the total amplitude) was necessary to fit the data, and for these cases only the major component was fitted to eq 4 (see the Supporting Information for details).

The rate constants for the opening of I:II and of HC.I:II (i.e., $k_{1}$ and $k_{2}$, respectively) were obtained from the fit to eq 4 . This treatment of the data assumes that the bound and free quadruplex are in equilibrium at all times (i.e., the rate of ligand binding and unbinding is much faster than that of the hybridization to either species; see the Supporting Information for justification and discussion).

To determine whether the system had had enough time to equilibrate at low temperatures, experiments were rerun for $15 \mu \mathrm{M} \mathrm{HC}$ at $10^{\circ} \mathrm{C}$ with delays of 0,1 , and $4 \mathrm{~h}$ between the mixing of I:II and $\mathbf{H C}$ and the collection of data. No significant difference was seen between these cases (data not shown), confirming that the system had indeed equilibrated, prior to quadruplex opening.

Van't Hoff and Arrhenius analyses of the data were used to obtain the thermodynamic parameters of binding and the activation energies for the opening of the unliganded (i.e., I:II, $k_{1}$ ) and liganded (i.e., HC.I:II, $k_{2}$ ) quadruplexes (see Table 1). A van't Hoff plot of the binding constant and Arrhenius plots of the rate constants are shown in Figure 5.

\section{Discussion}

Our system interrogates the unfolding of a quadruplex in the presence of an excess of trapping oligonucleotide, which therefore gives rise to pseudo-first-order conditions for quadruplex opening. A minimal kinetics model (Figure 3) was employed to quantitatively evaluate the influence of a quadruplex ligand on quadruplex opening. The activation energy for the opening of the human telomeric quadruplex, in the absence of ligand $(118 \pm 2 \mathrm{~kJ}$ $\left.\mathrm{mol}^{-1}\right)$, is close to the values determined in other related studies $\left(98 \pm 8 \mathrm{~kJ} \mathrm{~mol}^{-124}\right.$ and 102 $\mathrm{kJ} \mathrm{mol}^{-130}$ ). Also, the rate of quadruplex opening in the absence of the ligand at $20{ }^{\circ} \mathrm{C}$ $\left(0.009 \mathrm{~s}^{-1}\right)$ is in good agreement with that found for a similar quadruplex under comparable conditions $\left(0.008 \mathrm{~s}^{-130}\right)$. The binding constant of ligand $\mathbf{H C}$ to a human telomeric quadruplex has been previously measured to be $14.7 \pm 1.6 \mu \mathrm{M}$ at $25^{\circ} \mathrm{C}, 21$ which is in good agreement with the value of $11.8 \pm 4.9 \mu \mathrm{M}$ measured here. This supports that the kinetics scheme described in Figure 3 is a reasonable model. Kinetics analysis at several temperatures has allowed the determination of the enthalpy and entropy changes associated with ligand binding as $-77 \pm 22 \mathrm{~kJ} \mathrm{~mol}^{-1}$ and $-163 \pm 75 \mathrm{~J} \mathrm{~mol}^{-1} \mathrm{~K}^{-1}$, respectively. Calorimetric measurements have been made for a porphyrin quadruplex ligand, of comparable $K_{\mathrm{d}}$, under similar conditions where the enthalpy and entropy changes were measured at $-28.4 \mathrm{~kJ} \mathrm{~mol}^{-1}$ and $-8.4 \mathrm{~J} \mathrm{~mol}^{-1} \mathrm{~K}^{-1}$, respectively. 31 The apparent loss in entropy associated with $\mathbf{H C}$ binding is large, which is likely to be a reflection of the significant loss in conformational flexibility in the tetrapeptide portion of $\mathbf{H C}$ upon complexation with the quadruplex, accompanied by compensatory enthalpic interactions. We have previously proposed that the $\mathbf{H C}$ quadruplex binding mode is likely to involve 
loop-groove interactions, 21 which would lead to a reduction in quadruplex loop flexibility and contribute to entropy loss consistent with this new data. In contrast, the porphyrin ligand is a rigid system believed to interact with a quadruplex via stacking on a terminal tetrad,32 which would be expected to give a smaller entropy loss than the case of $\mathbf{H C}$ binding.

While the presence of $\mathbf{H C}$ clearly slows down the kinetics of quadruplex opening, it is interesting to note that the ligand causes a small change in the activation energy for quadruplex opening reaction $\left(118 \pm 2 \mathrm{~kJ} \mathrm{~mol}^{-1}\right.$ for the quadruplex alone and $98 \pm 10 \mathrm{~kJ}$ $\mathrm{mol}^{-1}$ for the quadruplex-ligand complex).33 Thus it seems likely that the ligand is still associated with the quadruplex in the rate-determining step of the quadruplex opening, as otherwise one would expect a ligand-induced increase in activation energy comparable in magnitude to the binding energy of the ligand. The quadruplex opening reaction may well proceed via a partially unfolded state that is then captured by hybridization driving the reaction to completion. A similar mechanism has been recently proposed for the disruption of the telomeric quadruplex by the human protein hPOT1.34 In the case of our study, the ligand $\mathbf{H C}$ may act by reducing the extent to which the quadruplex can partially unfold.

\section{Conclusion}

The opening of the human telomeric DNA G-quadruplex in the presence of a quadruplexbinding hemicyanine-peptide ligand has been investigated by FRET-based kinetics. The resulting data were fitted to a minimal model and used to derive kinetics and thermodynamics data to characterize the ligand-quadruplex interaction. The dissociation constant measured for the ligand and quadruplex agreed with an independently determined value, and the process of complex formation had a relatively large associated decrease in entropy. The ligand caused only a small change in the activation energy, implying that the ligand is still associated with the quadruplex in the transition state. We believe that the analysis of opening kinetics by FRET may be a more general approach to consider in the study of ligand-nucleic acid interactions.

\section{Acknowledgments}

We thank Cancer Research U.K. for a program grant (S.B. and S.L.). We thank the BBSRC, the Isaac Newton Trust, and Trinity College for funding J.J.G. S.B. and D.K. are BBSRC Research Development Fellows.

\section{References}

1. Sen D, Gilbert W. Nature. 1988; 334:364-366. [PubMed: 3393228]

2. Gellert M, Lipsett MN, Davies DR. Proc. Natl. Acad. Sci. U.S.A. 1962; 48:2013-2018. [PubMed: 13947099]

3. Van Dyke MW, Nelson LD, Weilbaecher RG, Mehta DV. J. Biol. Chem. 2004; 279:24323-24333. [PubMed: 15044472]

4. Tolstonog GV, Li G, Shoeman RL, Traub P. DNA Cell Biol. 2005; 24:85-110. [PubMed: 15699629]

5. Zaug AJ, Podell ER, Cech TR. Proc. Natl. Acad. Sci. U.S.A. 2005; 102:10864-10869. [PubMed: 16043710]

6. Parkinson GN, Lee MPH, Neidle S. Nature. 2002; 417:876-880. [PubMed: 12050675]

7. Zahler AM, Williamson JR, Cech TR, Prescott DM. Nature. 1991; 350:718-720. [PubMed: 2023635]

8. Huppert JL, Balasubramanian S. Nucleic Acids Res. 2005; 33:2908-2916. [PubMed: 15914667]

9. Todd AK, Johnston M, Neidle S. Nucleic Acids Res. 2005; 33:2901-2907. [PubMed: 15914666]

10. Simonsson T, Pecinka P, Kubista M. Nucleic Acids Res. 1998; 26:1167-1172. [PubMed: 9469822]

11. Cogoi S, Quadrifoglio F, Xodo LE. Biochemistry. 2004; 43:2512-2523. [PubMed: 14992588] 
12. Rankin S, Reszka AP, Huppert J, Zloh M, Parkinson GN, Todd AK, Ladame S, Balasubramanian S, Neidle S. J. Am. Chem. Soc. 2005; 127:10584-10589. [PubMed: 16045346]

13. Sun D, Guo K, Rusche JJ, Hurley LH. Nucleic Acids Res. 2005; 33:6070-6080. [PubMed: 16239639]

14. De Armond R, Wood S, Sun D, Hurley LH, Ebbinghaus SW. Biochemistry. 2005; 44:1634116350. [PubMed: 16331995]

15. Dai J, Dexheimer TS, Chen D, Carver M, Ambrus A, Jones RA, Yang D. J. Am. Chem. Soc. 2006; 128:1096-1098. [PubMed: 16433524]

16. Siddiqui-Jain A, Grand CL, Bearss DJ, Hurley LH. Proc. Natl. Acad. Sci. U.S.A. 2002; 99:1159311598. [PubMed: 12195017]

17. Phan AT, Modi YS, Patel DJ. J. Am. Chem. Soc. 2004; 126:8710-8716. [PubMed: 15250723]

18. Seenisamy J, Rezler EM, Powell TJ, Tye D, Gokhale V, Joshi CS, Siddiqui-Jain A, Hurley LH. J. Am. Chem. Soc. 2004; 126:8702-8709. [PubMed: 15250722]

19. Cuesta J, Read MA, Neidle S. Mini Rev. Med. Chem. 2003; 3:11-21. [PubMed: 12570851]

20. Neidle S, Parkinson GN. Nat. Rev. Drug Discovery. 2002; 1:383-393. [PubMed: 12120414]

21. Schouten JA, Ladame S, Mason SJ, Cooper MA, Balasubramanian S. J. Am. Chem. Soc. 2003; 125:5594-5595. [PubMed: 12733873]

22. Ourliac-Garnier I, Elizondo-Riojas MA, Redon S, Farrell NP, Bombard S. Biochemistry. 2005; 44:10620-10634. [PubMed: 16060671]

23. Ying LM, Green JJ, Li HT, Klenerman D, Balasubramanian S. Proc. Natl. Acad. Sci. U.S.A. 2003; 100:14629-14634. [PubMed: 14645716]

24. Green JJ, Ying LM, Klenerman D, Balasubramanian S. J. Am. Chem. Soc. 2003; 125:3763-3767. [PubMed: 12656607]

25. Lee JY, Okumus B, Kim DS, Ha T. Proc. Natl. Acad. Sci. U.S.A. 2005; 102:18938-18943. [PubMed: 16365301]

26. Rosu F, Gabelica V, Shin-ya K, De Pauw E. Chem. Commun. 2003; 21:2702-2703. [PubMed: 14649819]

27. Mergny JL, Maurizot JC. ChemBioChem. 2001; 2:124-132. [PubMed: 11828436]

28. Balagurumoorthy P, Brahmachari SK. J. Biol. Chem. 1994; 269:21858-21869. [PubMed: 8063830]

29. Wang Y, Patel DJ. Structure. 1993; 1:263-282. [PubMed: 8081740]

30. Li W, Miyoshi D, Nakano S, Sugimoto N. Biochemistry. 2003; 42:11736-11744. [PubMed: 14529284]

31. Haq I, Trent JO, Chowdhry BZ, Jenkins TC. J. Am. Chem. Soc. 1999; 121:1768-1779. It is noteworthy that our analysis was based on the thermodynamic data for the first binding event.

32. Phan AT, Kuryavyi V, Gaw HY, Patel DJ. Nat. Chem. Biol. 2005; 1:167-173. [PubMed: 16408022]

33. It was not possible to accurately obtain the activation enthalpy and entropy values owing to the relatively large associated errors.

34. Zaug AJ, Podell ER, Cech TR. Proc. Natl. Acad. Sci. U.S.A. 2005; 102:10864-10869. [PubMed: 16043710] 


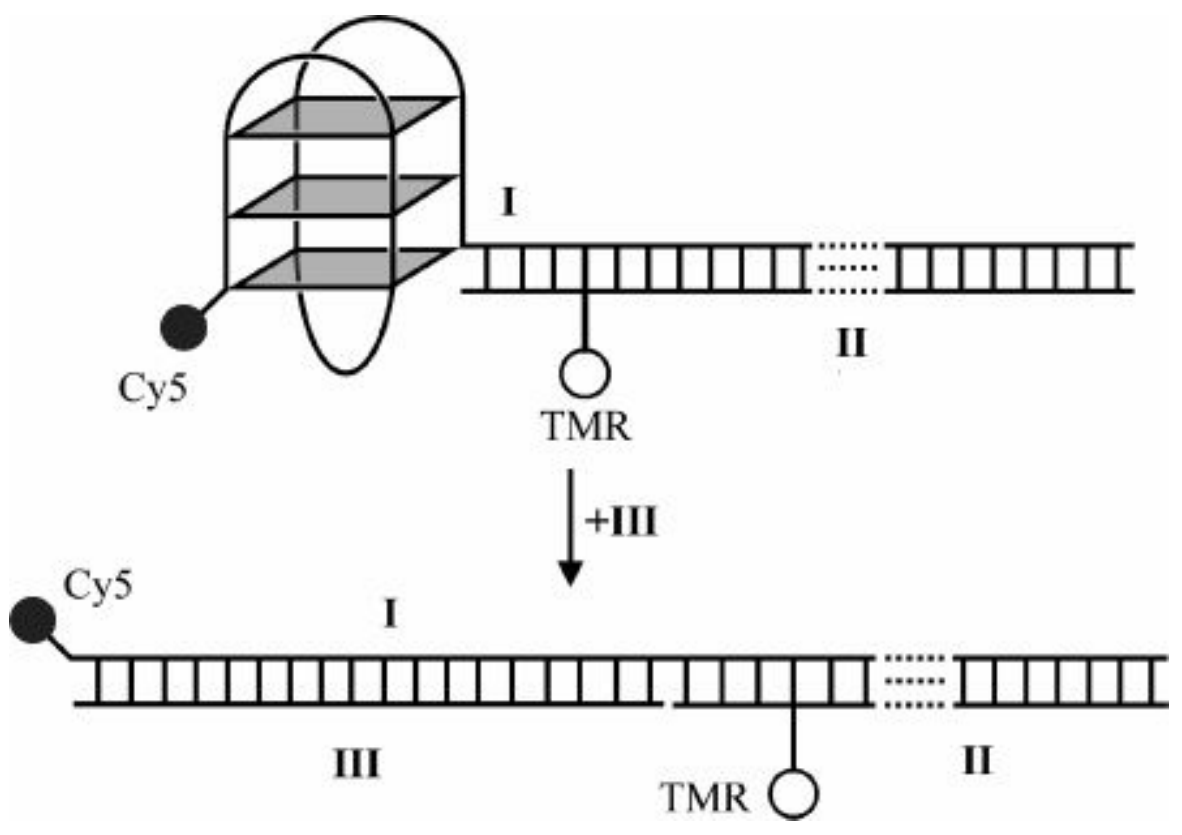

Figure 1.

FRET-based quadruplex system used in this study. Roman numerals represent the labels given to strands (see Materials and Methods), and TMR and Cy5 are the fluorophores that make up a FRET pair. Quadruplex opening is followed using the change in FRET efficiency between the TMR and Cy5. 


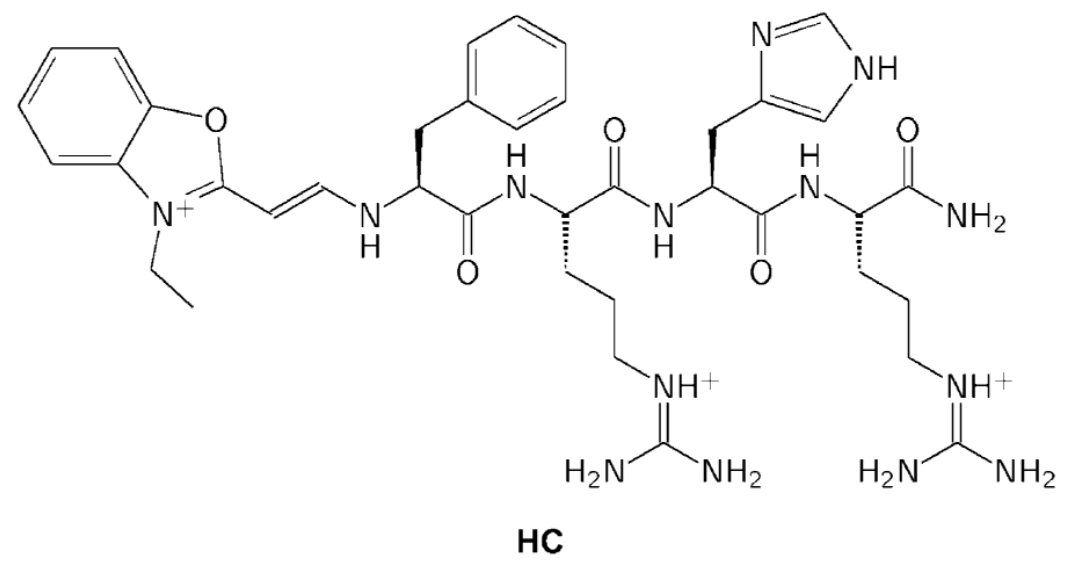

Figure 2.

Structure of the hemicyanine tetrapeptide conjugate HC.21 

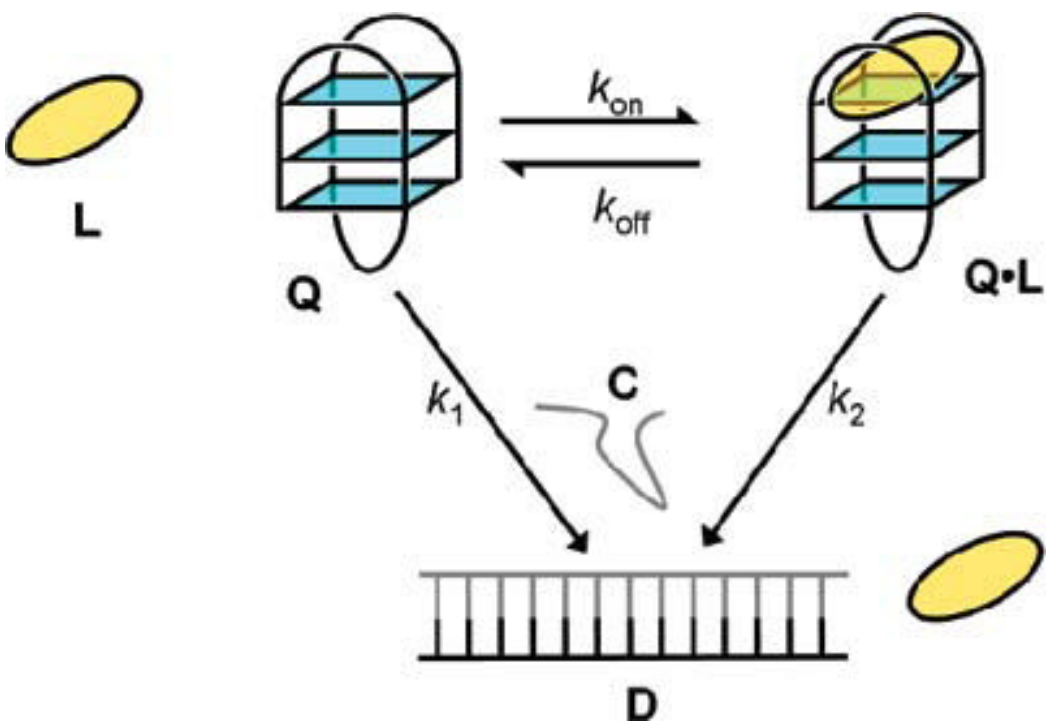

Figure 3.

Scheme used to derive a kinetic model of the opening of quadruplex $\mathbf{Q}$ in the presence of ligand $\mathbf{L}$ and complementary strand $\mathbf{C}$ to give duplex $\mathbf{D}$. 

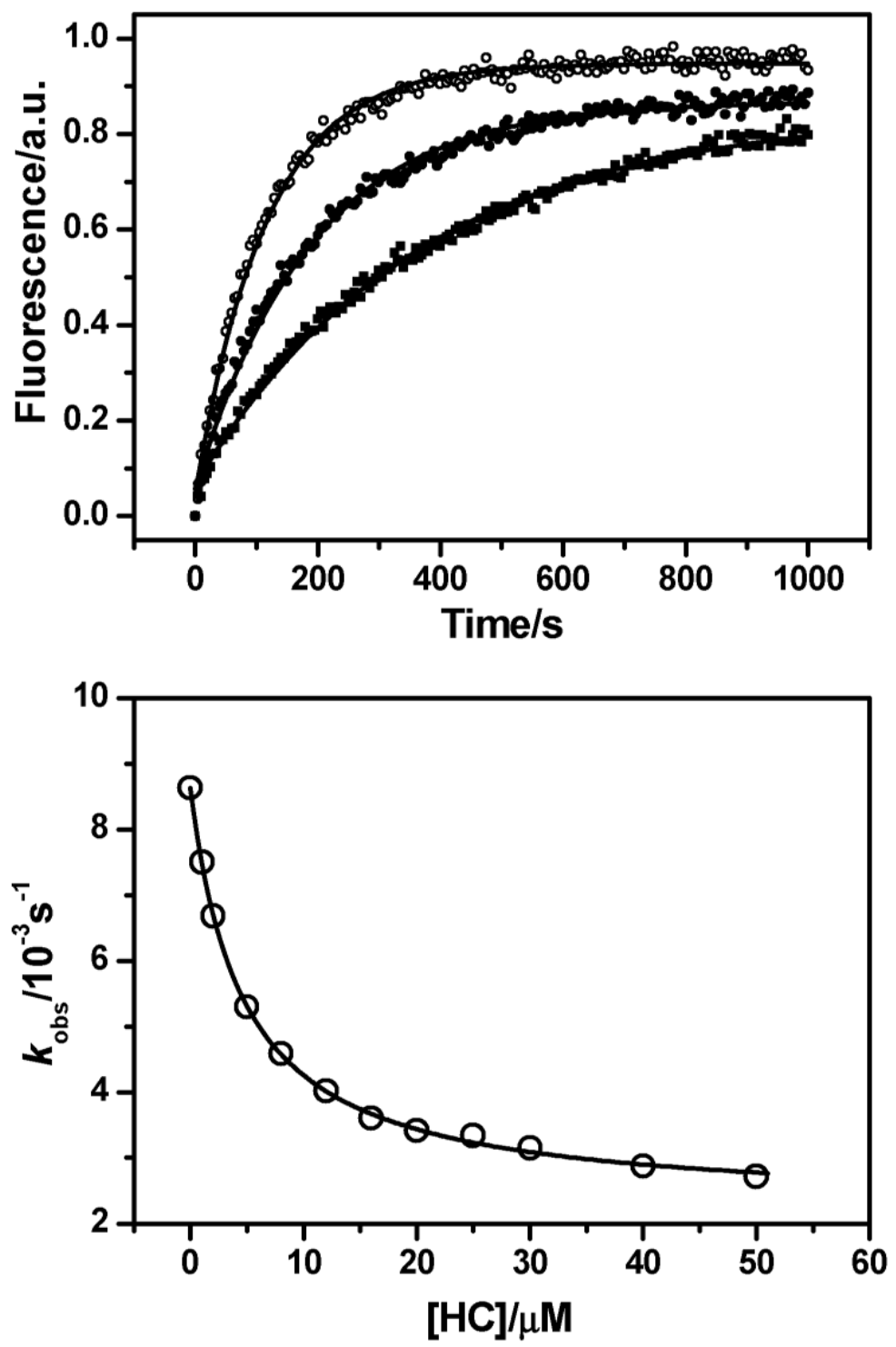

Figure 4.

Top: the increase of TMR fluorescence monitored at $580 \mathrm{~nm}$ as the quadruplex formed by I:II is opened by III in $10 \mathrm{mM}$ Tris. $\mathrm{HCl}(\mathrm{pH} 7.4)$ and $100 \mathrm{mM} \mathrm{NaCl}$ at $20{ }^{\circ} \mathrm{C}$. Data from runs performed in the presence of ligand $\mathbf{H C}$ at concentrations $0(\bigcirc), 5 \mu \mathrm{M}(\mathbf{O})$, and $50 \mu \mathrm{M}$ (ם) are shown, along with single-exponential fits (solid lines). In each series the initial fluorescence intensity has been subtracted from each data point. The rate constants of opening, $k_{\mathrm{obs}}$, were found to be $0.0086,0.0053$, and $0.0027 \mathrm{~s}^{-1}$ at 0,5 , and $50 \mu \mathrm{M} \mathrm{HC}$, respectively. Bottom: the variation of observed rate constant with concentration of $\mathbf{H C}$ for the hybridization of I:II to III at $20{ }^{\circ} \mathrm{C}$ in $10 \mathrm{mM}$ Tris. $\mathrm{HCl}(\mathrm{pH} \mathrm{7.4)}$ and $100 \mathrm{mM} \mathrm{NaCl}$. The data are shown as open circles and fits to eq 4 as a solid line. 


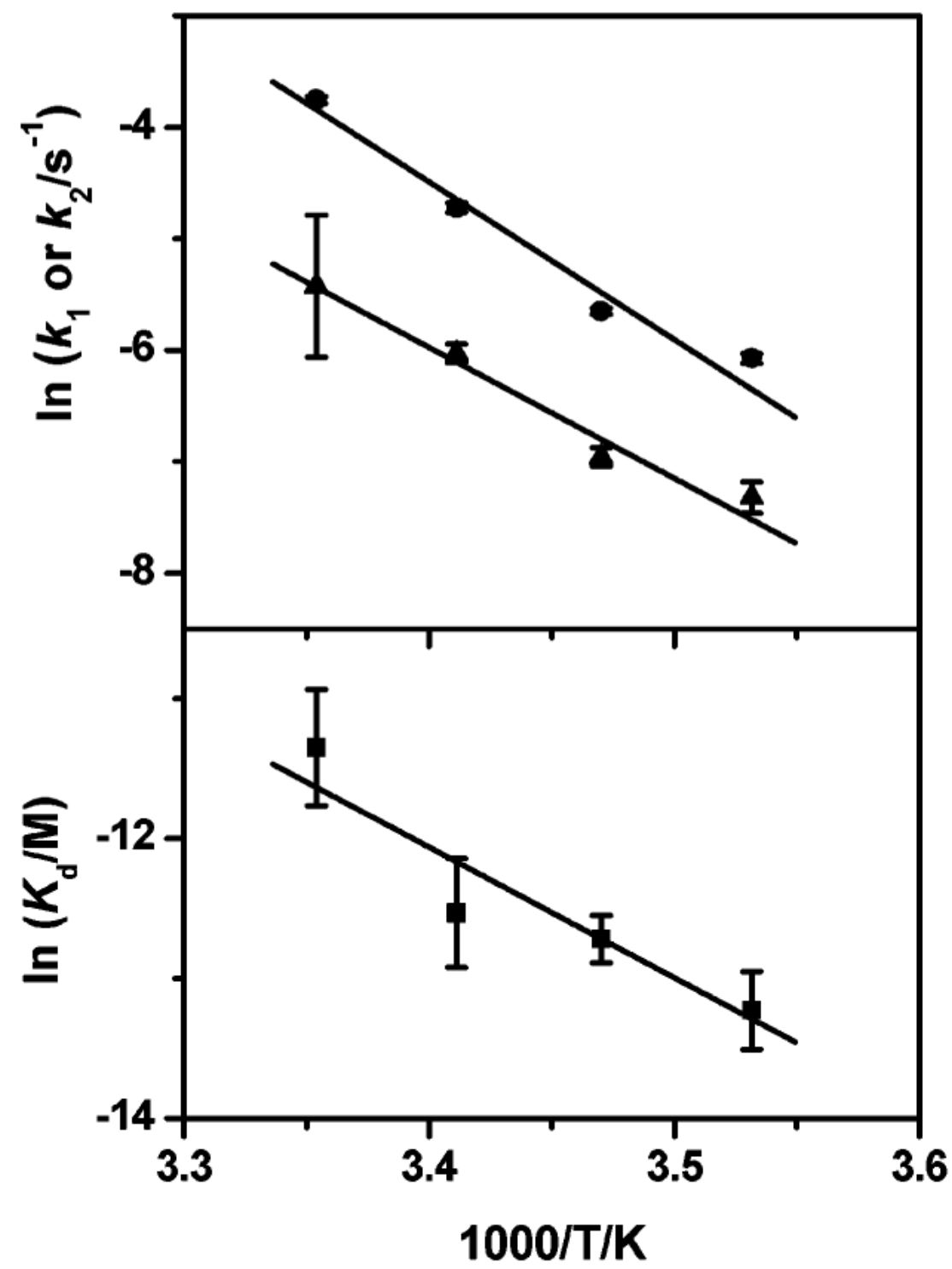

Figure 5.

Top: Arrhenius plots of the opening rates of I:II $\left(k_{1}, \mathbf{O}\right)$ and HC.I:II $\left(k_{2}, \boldsymbol{\Delta}\right)$, respectively. Bottom: van't Hoff plot of the dissociation constant $\left(K_{\mathrm{d}}, \mathbf{\square}\right)$ of $\mathbf{H C}$ to I:II. Activation energies for $k_{1}$ and $k_{2}$ obtained from the fits are $118 \pm 2$ and $98 \pm 10 \mathrm{~kJ} \mathrm{~mol}^{-1}$, respectively, and the thermodynamic parameters found are $\Delta H=-77 \pm 22 \mathrm{~kJ} \mathrm{~mol}^{-1}$ and $\Delta S=-163 \pm 75$ $\mathrm{J} \mathrm{mol}^{-1} \mathrm{~K}^{-1}$. 


\section{Table 1}

Parameters Obtained from Curve Fits of Eq 4 to Plots of Quadruplex Opening in $10 \mathrm{mM}$ Tris $\cdot \mathrm{HCl}(\mathrm{pH}$ 7.4) and $100 \mathrm{mM} \mathrm{NaCl}$

\begin{tabular}{crcr}
\hline temperature $/{ }^{\mathbf{C}} \mathbf{C}$ & $\boldsymbol{k}_{\mathbf{1}} /\left(\mathbf{1 0}^{\mathbf{- 3}} \mathbf{s}^{\mathbf{- 1}}\right)$ & $\boldsymbol{k}_{\mathbf{2}} /\left(\mathbf{1 0}^{\mathbf{- 3}} \mathbf{s}^{\mathbf{- 1}}\right)$ & $\boldsymbol{K}_{\mathrm{d}} \boldsymbol{\mu} \mathbf{M}$ \\
\hline 10 & $2.3 \pm 0.1$ & $0.66 \pm 0.09$ & $1.8 \pm 0.5$ \\
15 & $3.5 \pm 0.1$ & $0.95 \pm 0.08$ & $3.0 \pm 0.5$ \\
20 & $8.9 \pm 0.4$ & $2.4 \pm 0.2$ & $3.6 \pm 1.4$ \\
25 & $23.4 \pm 0.7$ & $4.4 \pm 2.8$ & $11.8 \pm 4.9$ \\
\hline
\end{tabular}

